\title{
ARCH PLAY: APPLICATIONS OF NARRATIVE THEORY IN VIDEO GAME AESTHETICS
}

\author{
by \\ Evan Fradley-Pereira \\ B.A.h. Cultural Studies, Trent University, 2011 \\ A Major Research Paper \\ Presented to Ryerson University \\ In partial fulfillment of the requirements \\ for the degree of \\ Master of Digital Media \\ In the Yeates School of Graduate Studies \\ Toronto, Ontario, Canada, 2016 \\ (C) Evan Fradley-Pereira, 2016
}




\section{Author's Declaration}

I hereby declare that I am the sole author of this MRP. This is a true copy of the MRP, including any required final revisions.

I authorize Ryerson University to lend this MRP to other institutions or individuals for the purpose of scholarly research.

I further authorize Ryerson University to reproduce this MRP by photocopying or by other means, in total or in part, at the request of other institutions or individuals for the purpose of scholarly research.

I understand that my MRP may be made electronically available to the public.

- Evan Fradley-Pereira 


\title{
Abstract
}

\author{
ARCH PLAY: APPLICATIONS OF NARRATIVE THEORY IN VIDEO GAME \\ AESTHETICS \\ Master of Digital Media, 2016 \\ Evan Fradley-Pereira \\ Digital Media, Ryerson University
}

As of 2015, the incumbent international eSports paradigm centers on genre-defining systems and games that were not initially designed for mass spectatorship. As a result, would-be fans are often confronted with a high-friction onboarding process verging on hostility. With global viewership estimated to reach over 238m unique annual viewers by 2017 (Superdata, 2015), leading developers have adapted the designs of new products to prioritize audiences as well as players. The most successful among them have capitalized off of the resulting spectator virality. Lacking is a high-level framework for evaluating games based on aesthetic composition and their resulting viability as a spectator experience.

This paper offers critical evaluations of dominant and lesser-known gaming spectator experiences via in-depth analyses of their constituent design affordances relating to a combined, interdisciplinary aesthetic framework centered heavily around narrative-bias. It is asserted throughout that any viewing experience with certain aesthetic factors configured to prioritize a clear and approachable classical narrative design, when evaluated aesthetically, can be considered rich in quality. Conforming to this aesthetic standard also permits games the potential to enjoy mass popularity. This paper is intended to serve as a foundation for an interdisciplinary framework of best practices in video game design. 


\section{Acknowledgements}

Completion of this paper would not have been possible without the support of Alya Naumova and the academic oversight of Adam Clare. 


\section{Dedication}

Dedicated to my lovely wife,

For her endless support and encouragement of my many expensive curiosities. 


\section{Table of Contents}

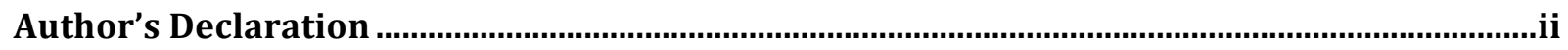

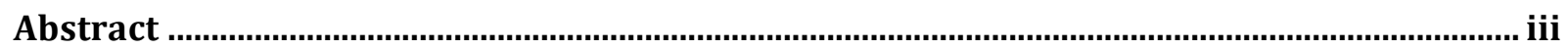

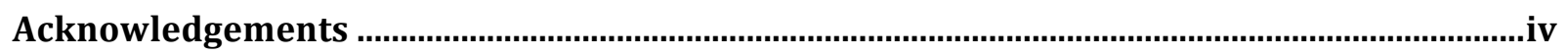

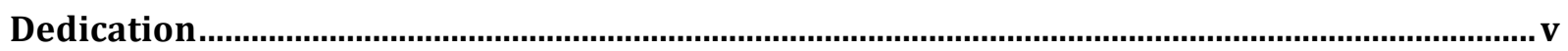

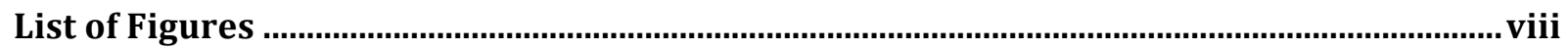

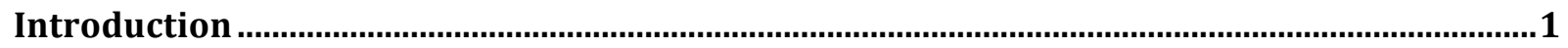

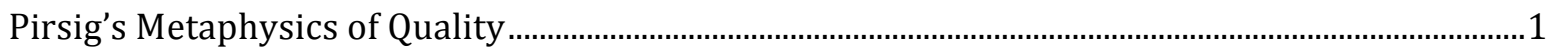

MDA Framework

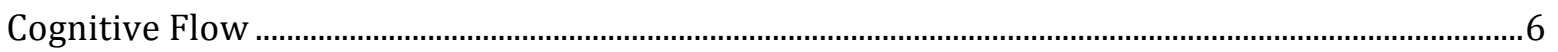

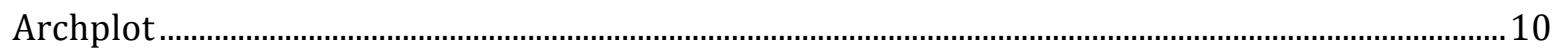

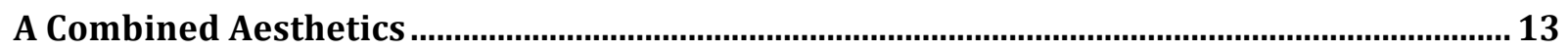

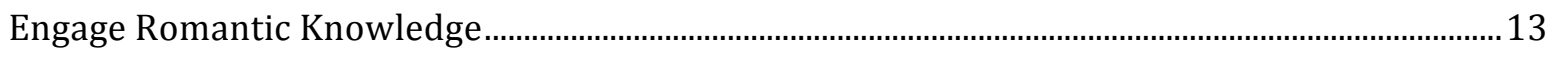

Engage Classical Knowledge

Clear, Consistent, and Manageable Mechanics ……............................................................................... 15

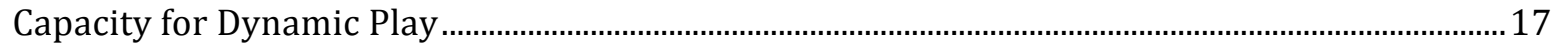

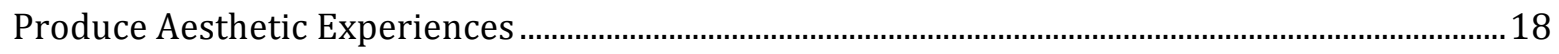

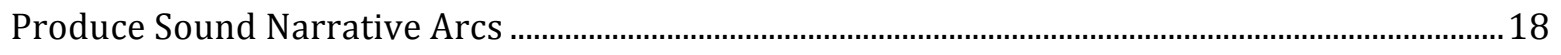

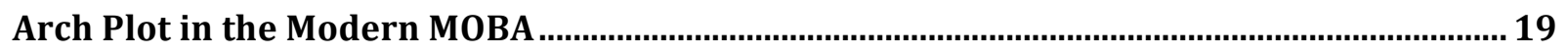

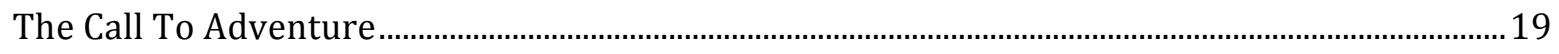

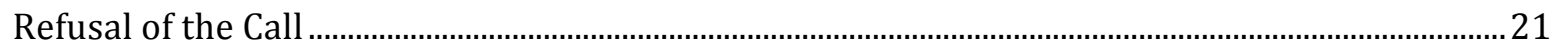

Supernatural Aid

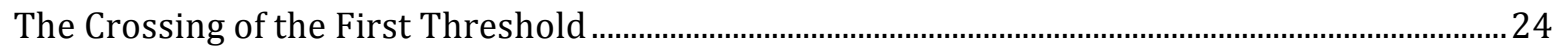

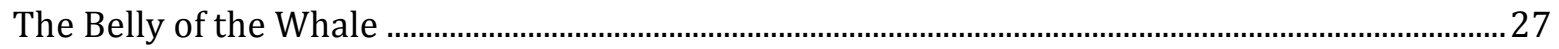




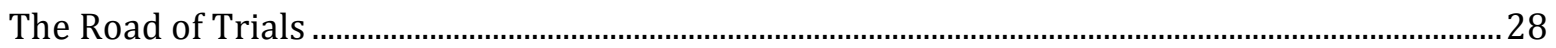

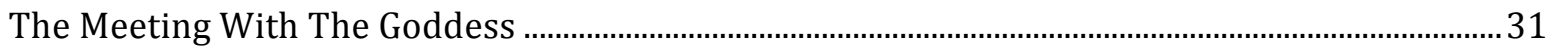

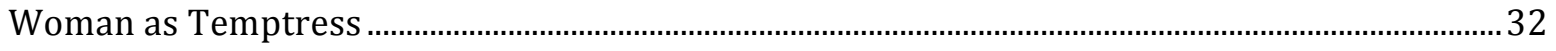

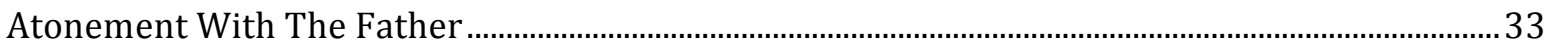

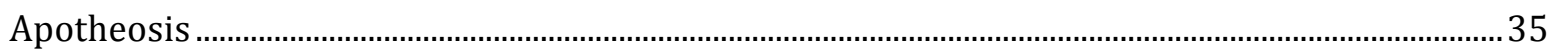

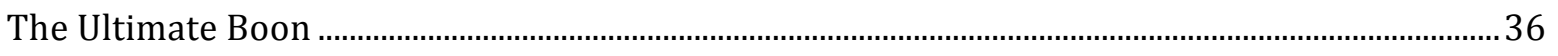

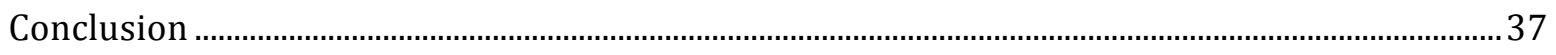

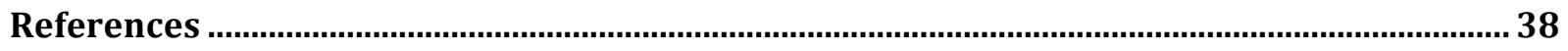

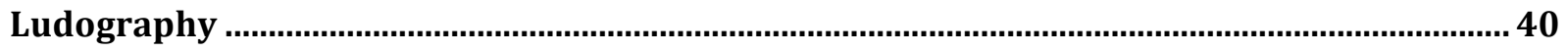




\section{List of Figures}

Figure 1 - A visualization of Csikszentmihalyi's model of mental flow.

Figure 2 - A comparison of free-to-play mobile game iconography.

Figure 3 - A tree of life, as it appears in Warcraft 3 


\section{Introduction}

This paper endeavours to detail practical thought technologies for the critical evaluation and development of "good" video games, with special attention paid to the application of narrative theory as it relates to video game aesthetics. It is understood by the author that there exists no shortage of academic writing on the topic of aesthetics, and that in order to attempt an argument for or against any cultural artefact as being objectively "good" or "bad", some thought must first be spent on what is meant by saying so. This paper works from a position of knowledge that combines complementary, interdisciplinary frameworks in an effort to effectively discuss the topic of "quality" in game design. It is the position of the author that by combining these models, an effective structure of quality ludological interaction can be outlined and applied to real-world products later in the paper.

\section{Pirsig's Metaphysics of Quality}

The philosophical foundation of aesthetic understanding that the subsequent arguments of this paper are built upon comes from the 1974 philosophical narrative "Zen and the Art of Motorcycle Maintenance" by Robert M. Pirsig as well as one of his later books, "Lila: An Inquiry Into Morals". Between the two, Pirsig constructs a theoretical framework known as the Metaphysics of Quality, in which he asserts that a rational definition of quality is impossible and that quality itself precedes empirical intellectual process and in doing so exists only at the "knife-edge" of experience. All subsequent discussions of quality found in this paper are to be predicated on a subscription to the 
belief that quality is not best analyzed along a traditional subjective/objective spectrum, but that quality precedes rationality as a dialectical monism, best summarized by the following quotation:

Good is a noun. That was it... That was the homer, over the fence, that ended the ball game. Good as a noun rather than as an adjective is all the Metaphysics of Quality is about. Of course, the ultimate Quality isn't a noun or an adjective or anything else definable, but if you had to reduce the whole Metaphysics of Quality to a single sentence, that would be it. (Pirsig, 1991)

Pirsig simultaneously delineates two discrete schools of thought concerning beauty: romantic and classical. He personifies romantic beauty in the form of two fictional characters that the author and his son are joined by during a trans-American motorcycle trip. The Sutherlands, as they're known, are propelled by an aversion to technology and a desire to escape from a perceived emotional death brought on by the increasingly systematic and rational demands of their environment as post-industrial city dwellers. They exist in contrast to the author's own classical sense of beauty, which is capable of appreciating the rational relationships of numbers, geometry, mechanical engineering, etc... He argues that due to the antecedent and definitively null nature of quality itself, neither convention is more valid than the other and that thanks to this understanding "the entire field called esthetics is wiped out... completely disenfranchised... kaput." (Pirsig, 213) In addition to refuting the validity of rational aesthetic analysis, Pirsig argues the benefits of aesthetic pragmatism, demonstrating that empirical phenomena derived from 
certain activities (like motorcycle maintenance) may seem drudgerous to some and beautiful to others, and that balance depends entirely on the attitude of the individual.

Much like any other craft, there exists patterns of game design capable of creating a greater wealth of "good" than others, and they require a dedication to craft that is both selfless and self-interested. By working first from a rational, systems-minded position before tempering the results with a romantic, in-the-moment sensibility, the game designer learns to create products that excel in their function. The decision to "care", as Pirsig calls it, is what differentiates quality craftsmanship from rote, systemically-motivated manufacture. Pirsig's son personifies this naive character flaw in his vain attitude toward their journey to the top of a literal mountain. Pirsig claims early on that "Any effort that has self-glorification as its final endpoint is bound to end in disaster." (Pirsig, 210) Video games, by combining moments of romantic and classical beauty through simultaneous mediums of communication and a tight feedback loop, can be designed to include mutually complementary systems capable of acting in concert to elicit "good" that is both greater in frequency and severity than one that does not. This comports with the author's own assertions in the text:

Such personal transcendence of conflicts with technology doesn't have to involve motorcycles, of course. It can be at a level as simple as sharpening a kitchen knife or sewing a dress or mending a broken chair. The underlying problems are the same. In each case there's a beautiful way of doing it and an ugly way of doing it, and in arriving at the high-quality, beautiful way of doing 
it, both an ability to see what 'looks good' and an ability to understand the underlying methods to arrive at that 'good' are needed. Both classic and romantic understands of Quality must be combined. - Pirsig, 292

\section{MDA Framework}

Authored by Robin Hunicke, Marc LeBlanc, and Robert Zubek, the MDA framework asserts that video games and other interactive products can be broken down into their constituent mechanics, dynamics, and aesthetics. The model of interaction laid out by the authors places the designer at one end of a spectrum and places mechanics, dynamics, and aesthetics between them and the player in that order. Pirsig's sentiments are echoed in the MDA framework, which defines game mechanics as a highly classical section of the craft. Mechanical practitioners benefit from a wealth of systematic knowledge derived from extensive experience building and analyzing game systems. They go on to describe dynamics as the something resembling Pirsig's "knife-edge" of quality, in which behaviours emerge among players in response to the mechanical systems in place. Behaviours like camping (a dynamic) in a first-person-shooter (a mechanic) or gold farming in an MMORPG.

Both mechanics and dynamics, however, are ultimately in service of aesthetics. Best described as the emotional output elicited in the players by the game, the authors assert that there exists 8 primary aesthetic phenomena that until now have fallen under the definition of "fun". MDA makes admirable progress in distancing the discourse from inferior vocabularies and towards "a more directed vocabulary" in their efforts to delineate 
the emotional phenomena produced in players. The eight primary aesthetics the authors list (with the admission that many others do exist) as the following:

1. Sensation - Game as sense-pleasure

2. Fantasy - Game as make-believe

3. Narrative - Game as drama

4. Challenge - Game as obstacle course

5. Fellowship - Game as social framework

6. Discovery - Game as uncharted territory

7. Expression - Game as self-discovery

8. Submission - Game as pastime

The authors of the MDA are admirably trying their hand at the same problem as Pirsig. In seeking to define a taxonomy of emotional sensation, each experientially unique, MDA attempts to pin down quality and render it intellectually malleable. One of the realizations that leads Pirsig to assert that quality itself escapes definition is the fact that "When analytic thought, the knife, is applied to experience, something is always killed in the process." (Pirsig) It is Pirsig's belief that the measurement of quality escapes even the most finite floating-point numerical system. Pirsig relays the sentiments of Kant in noting that "What we think of as reality is a continuous synthesis of elements from a fixed hierarchy of a priori concepts and the ever changing data of the senses." (Pirsig, 133) It is for this reason that the assertions of the MDA framework, while helpful, need to be 
tempered with the understanding they are imperfect and present only an approximation of what will ultimately be the emotional product in the player.

That said, MDA's taxonomy of aesthetic components is the most helpful vocabulary currently available for discussing a game's ability to produce moments of quality. While Pirsig's Metaphysics of Quality refute the intellectualization of quality at its most abstract, MDA offers a downstream taxonomy that, unlike the arguments of estheticians that Pirsig so gladly cuts down, does not argue for the superiority of one aesthetic over another. With the understanding that absolute communicative fidelity is impossible, this paper presumes to operate with the understanding that beauty resulting from quality can be divided into sub-categories only once it has moved past Pirsig's "knife-edge" of experience. While we, by definition, cannot penetrate the moment of quality, we are capable of measuring the resulting empirical sensations enacted by players. For this reason, let it be understood that a game of "quality" is one that can produce great and many emotional experiences. Aesthetics are a downstream phenomena, in which an audience unconsciously groups data from the never-ending empirical firehouse and and classifies it according to learned taxonomies.

\section{Cognitive Flow}

Absent from the 8 primary aesthetics outlined by the authors of the MDA framework is the aesthetic of efficacy, or what might be described as the pleasure resulting from efficiently overcoming challenges and accomplishing tasks germain to a larger goal. It's an emotional phenomena that while not necessarily unique to games, should be 
considered one of the medium's defining characteristics. Whether or not it constitutes what the authors had intended as their definition of aesthetics is debatable, but the ability to engineer interactive systems biased towards producing states of cognitive flow is the definitive goal of game professionals, and is central to any discussion of quality as it relates to games. Thankfully, there exists a body of theoretical knowledge dedicated to the intricate dissection of this aesthetic, and in itself represents an argument for further dissection of game aesthetics at large.

To fill in this gap, we have the work of Hungarian psychologist Mihaly Csikszentmihalyi, whose speculative exploration of psychological phenomena surrounding task completion in the 1970 s evolved into a body of published work dealing primarily with states of cognitive flow, which is a state of emotional and intellectual activity that occurs when an individual is either working, playing, or participating in a creative activity. While it is tempting to call this state "enjoyable" or "pleasurable", these would constitute definitive failings according to Pirsig. Flow would then be best described as a sensation of great quality, and is achieved when the difficulty of the task at hand is balanced equally against the skill of the participant. The imbalance created by either an excess of difficulty or skill shifts the participant beyond the state of flow, and they no longer perceive it as being pleasurable. If the difficulty of the task is too great that the participant is incapable of making any progress, the anti-aesthetic of frustration occurs and the participant is unlikely to revisit the task. The same is true if the participant's skill is too great for the task at hand. Work that is too easy does not produce flow. 


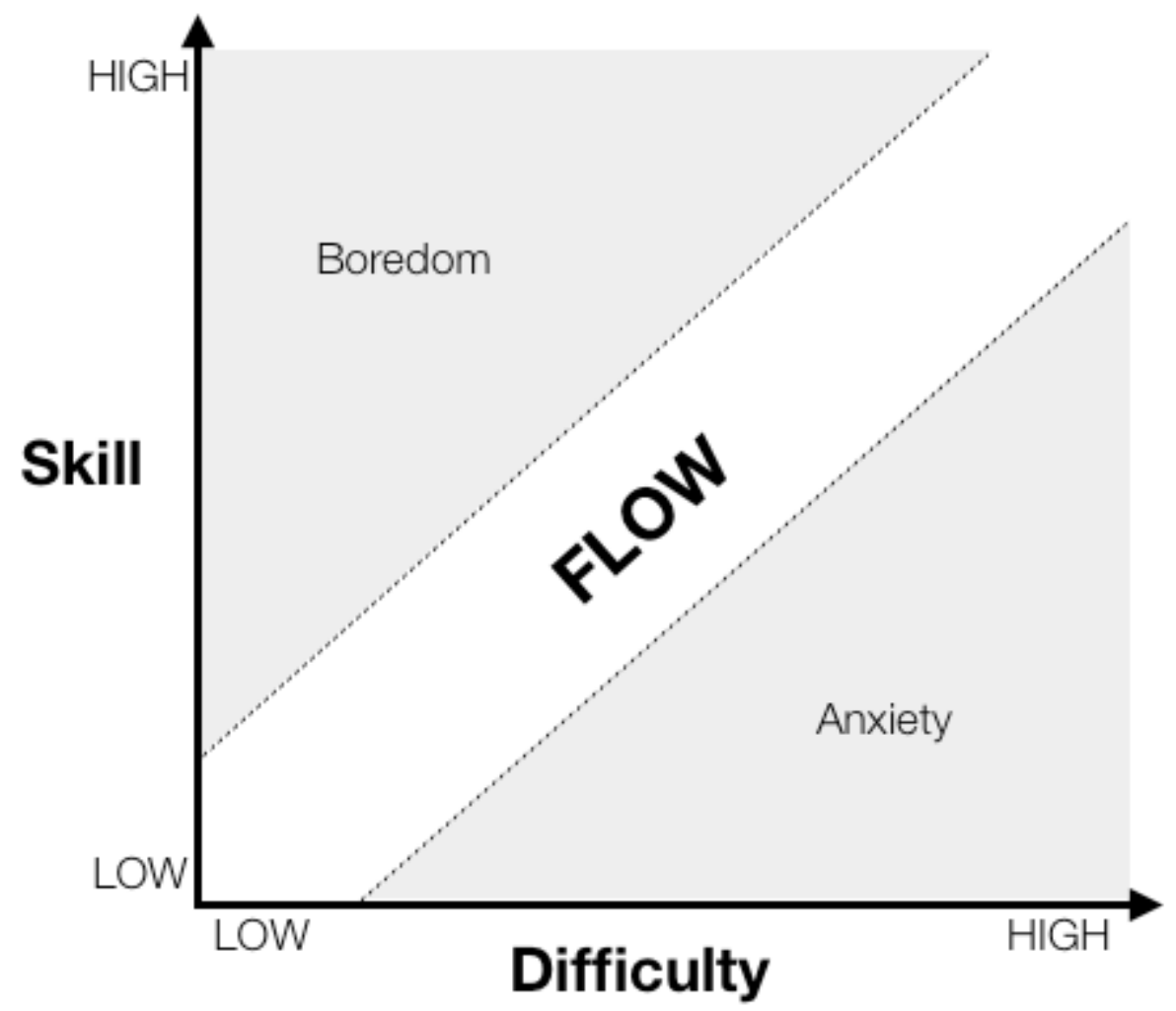

Figure 1

Csikszentmihalyi outlines four key characteristics of interactions that are biased towards producing states of cognitive flow. They are:

1. Concrete goals with manageable rules.

2. Demands for actions to achieve goals that fit within the person's capabilities.

3. Clear and timely feedback on performance and goal accomplishment.

4. Minimal extraneous distraction, thus facilitating concentration.

The first rule is analogous both with Pirsig's assertion that classical knowledge is equally important to romantic knowledge, and MDA's assertion that interaction begins 
with well-constructed mechanics. Csikszentmihalyi adds two additional virtues to the craft of mechanics, in stating that they must be concrete and manageable, speaking the importance of preventing technical frustration in the player. Csikszentmihalyi shares this sentiment with Pirsig, who demonstrates how technical frustration can lead to the same naive understanding of the Sutherlands, who villainize technological complexities and consider them something to be escaped. This naivety confounds the potential for flow and/or for the aesthetic potential inherent in the cohesion between romantic and classical knowledge that Pirsig calls quality.

Csikszentmihalyi offers a solution in his second rule, which states that it is the duty of the craftsperson to first identify the person's skill level and demand only what they are capable of by exerting an appropriate amount effort conducive to a flow state. Their third rule affirms the importance of the feedback loop, noting that flow cannot exist with the rational and romantic knowledge that the participant's efforts were sufficient to accomplish the task at hand. The fourth preaches the importance of concision in all things, minimizing signal-to-noise in order to maintain a highly efficient channel of interaction and communication. All four characteristics, when applied to the design and development of an interactive experience, constitute an integral aspect of an additional aesthetic framework from the world of narrative theory known as Archplot, which represents a classical arrangement of narrative systems capable of producing romantic beauty in an audience. 


\section{Archplot}

Inherent in every game's design is its propensity for players to enact structurallysound narrative arcs, specifically those that follow the laws of classical design. These "archplots" are described by McKee (1997) as:

...a story built around an active protagonist who struggles against primarily external forces of antagonism to pursue his or her desire, through continuous time, within a consistent and causally connected fictional reality, to a closed ending of absolute, irreversible change. (p.48)

A close reading reveals that the same circumstances and motivations required of an archplot protagonist are required of to induce a state of cognitive flow as it is described by Csikszentmihalyi. What he calls "concrete goals" in his first characteristic of flow, McKee calls being an "active protagonist", or one that behaves in such a way that they exert their will on their environment in pursuit of an external goal. What Csikszentmihalyi calls manageable rules, McKee articulates as as "continuous time, within a consistent and causally connected fictional reality". Even the fourth characteristic of cognitive flow, "Diminish extraneous distraction, thus facilitating concentration," translates to the construction of effective plotlines. The value of concision is widely held among the narrative community, articulated by Strunk and White in the Elements of Style as "Rule 17", which states: 
Vigorous writing is concise. A sentence should contain no unnecessary words, a paragraph no unnecessary sentences, for the same reason that a drawing should have no unnecessary lines and a machine no unnecessary parts. This requires not that the writer make all sentences short, or avoid all detail and treat subjects only in outline, but that every word tell. -Strunk and White, The Elements of Style

McKee articulated the Archplot style of storytelling in reference to the passive media of film and television, as well as their progenitors, theatre and oral narrative. In deciding to watch, the spectators of a sport create passive media from active media, and thereby make relevant the standards of narrative structure. Analyzed at a granular level, we see that McKee's definition fits the mold of eSports well. An "active" protagonist is one that willingly, and with full control of their faculties, pursues a goal. For competitive eSports players, this is most often victory over the opposing team, who represent the "external forces of antagonism". Their origin in active media binds derivative forms of passive media in "continuous time and causally connected (fictional) reality". A game cannot be replayed once it is concluded, checking the box of "absolute, irreversible change."

Game systems with stronger biases towards producing these narrative arcs deliver aesthetically superior spectator experiences. "Like Roman gladiators, boxers will win the admiration and love of the crowd only if they have been in the dramatic situation of facing personal physical destruction." (Gumbrecht, 2006) It is a skilled game designer that assembles abstract systems that are statistically more likely to produce these types of 
narrative dynamics. Just like narrative, however, what is excluded is often of greater consequence than what is included. McKee reminds us that "genius consists not only of the power to create expressive beats and scenes, but of the taste, judgement, and will to weed out and destroy banalities, conceits, false notes, and lies." Where passive media reflects the hand of its auteur in the details, active media relinquishes these details to the choices made by users in each unique instantiation of the product. Where game designers can succeed is in each implementation of what Mark Barden refers to as "A Beautiful Constraint". By designing systems that influence users towards behaviour that produces appropriate story beats and prevents periods of stagnation or narrative non-action, these "invisible gifts" can produce objectively superior spectator experiences by effectively guiding the player through the three-act structure. 


\section{A Combined Aesthetics}

In combining these four frameworks, a practical set of aesthetic guidelines can be formed. Through their interplay, we are able to better understand and critically analyze the constituent systems of contemporary interactive products. It is the author's intent to produce a critical framework conducive to

\section{Engage Romantic Knowledge}

Well-designed games include systems that reward familiarity with the "feel" of the game's immediate feedback loop. By endeavouring to bring aesthetic, emotional experiences as close as possible to Pirsig's "razor-edge of experience", one half of his requirements for qualitative balance, which states that romantic and classical knowledge should be combined, are met. Most challenging for the designer is the fact that these systems of quality do not produce empirically measurable data within the player. The practice of playtesting is anything but lossless, as Pirsig has pointed out that the process of intellectualization is inherently destructive to quality. Nonverbal communications, including body-language and auditory ejaculations of any sort are arguably the vocabulary closest to the romantic experience. With that limitation in mind, a few catalyzing variables can be identified by their capacity to confound romantic knowledge either through their absence or their inferior implementation. Among them is the fidelity of control a player has between themselves and the digital environment they occupy, either through an avatar or disembodied user interface. A low fidelity of control or even an inability to affect minor change in a digital environment has the potential to produce sensations of frustration in the player. It's a common complaint heard from anyone asked to communicate their empirical 
experience, often heard from professional game reviewers as being "clumsy" and most often when found in a game where high-twitch controls are necessary to complete the game's challenges. Extended periods of inaction including long load-times, character selection screens, lobbies, elevators, etc... all contribute to a loss of romantic, "in the moment", engagement. Systems conducive to romantic engagement occupy the space that MDA would categorize as the "sense-pleasure" aesthetic. Visual, auditory, and haptic feedback all contribute to romantic engagement.

\section{Engage Classical Knowledge}

Pirsig uses the metaphor of a train to describe how classical knowledge fits into his model of metaphysical aesthetics. Romantic quality, he says, is the absolute vanguard of the train as it moves along the rail. It is the point in space and time where it simultaneously is and is not a train. Extending the metaphor, he explains that classical knowledge is everything behind that point. The engine, box cars, passenger cars, and everything down to the caboose is classical knowledge. It's everything we pick up along the way: a wealth of banked data that we may call upon in the operation of our day-to-day lives. For a video game to achieve Pirsig's aesthetic ideal of engaging both classical and romantic knowledge, it needs to contain systemic complexities sufficient that players benefit from accruing intimate knowledge of those systems and being able to navigate them with alacrity.

Intentionally or otherwise, this is what the popular marketing adage "Easy to learn, hard to master" attempts to capitalize off of. The promise of a past-time that rewards persistence and the mental agility necessary to internalize complex relational 
systems is universally appealing. For game designers, the challenge has long been to balance systemic complexity against visceral engagement, but more contemporary products demonstrate an intimate understanding of this duality. The burgeoning genre of digital card games has been at the forefront of this development, including Blizzard's massively popular collectible card game "Hearthstone". By digitizing what was formerly a strictly real-world experience, Blizzard was able to leverage powerful information technologies outside of the game to foster desired behaviours related to classical knowledge. Enabling the development of powerful social networks through the creation of strong-ties resulting from shared game-relevant classical knowledge is mandatory for any contemporary AAA game release. As one author describes, "For many players, however, as well as their opponents, digitisation, with its support for informating and theorycrafting, has fundamentally changed their engagement with and experience of the game.” (Robertson, Gibs, Smith, 2015)

\section{Clear, Consistent, and Manageable Mechanics}

Insofar as it can be measured, a game's quality is a function of its ability to be understood and engaged with by its audience. Integral to comprehension and engagement is the product's clarity, internal consistency, and approachability relative to its audience. Clarity is achieved one of two ways: either through the alignment of design decisions with the conventions of its parent semiosphere or through highly-modal design choices. The more a game can leverage existing codes shared by games of a similar genre or platform, the less likely it is that semiotic disconnects will occur. By way of example, most mobile free-to-play games have adopted a consistent iconographical code related to elements of the game's UI that enable in-app purchases. The "plus" symbol (+) is most often used to 
denote a UI element that will transition the game-state into one in which the player can purchase virtual goods for real-world currency
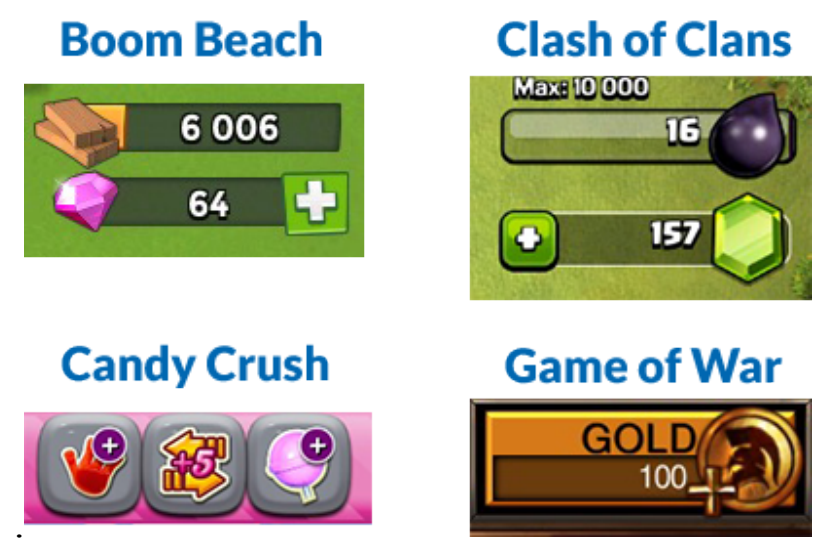

Figure 2 - Comparison of F2P Iconography

Internal consistency is also paramount in maintaining an effective feedback loop between player a product. Much like the rules of narrative structure, which dictate that a narrative's internal laws must remain consistent once they are established or else risk the deflation of dramatic value, so to must interactive products. To change the rules for reasons beyond the game's internal logic robs the player of the value associated with their hereto for accrued classical knowledge. It establishes a convention of random, unpredictable behaviour that cannot be planned for or adapted to. An interactive system with no calculable predictability is not one that rewards classical knowledge, or "skill", and it omits the potential for aesthetic experiences. Games of chance, as they soon become, engage romantic faculties almost exclusively, and while they may maintain appeal for smaller audiences, they become incapable of embodying quality as we have come to understand it. 
Last, a game's mechanics must be of a manageable scope. This can be understood to mean that any complexity that becomes excessive to the point that more information is being conveyed than can be meaningfully retained or digested results in loss of information, and is antithetical to quality. Where designers can affect positive change in the construction of manageable mechanics in their digital products is through the measured and well-tested arrangement of a player's onboarding experience. Known among industry professionals as a game's FTUE, or first-time user experience, it is crucial that mechanics be introduced one at a time, at a manageable rate. While late-stage complexity should considered a design virtue, at no point should the interplay of systems become so complex that the player cannot comprehend causal relationships between a game's internal systems.

\section{Capacity for Dynamic Play}

Quality games contain systems of sufficient complexity to produce in its players moments of inference and discovery. The "joy of inference" is a design value also rooted in narrative craft. Known by many as "the iceberg theory", it is the belief that the absolute minimum amount of content should appear on the page or screen, and only in so far as it is able to elicit instances of "closure" in the audience (McCloud, 1993). The literary work of Ernest Hemingway is among the most notable examples of this design aesthetic, and is widely held in high esteem for its economy of language. The same principles, when applied to game design, dictate that players should be left to study and discover meaningful interplay of systems on their own. This results in greater valuation of the resulting classical knowledge, which in turn becomes an additive variable in the derivation of aesthetic experiences. 


\section{Produce Aesthetic Experiences}

For a game to be considered of high quality, it must, by definition, produce in its players instances of emotionally aesthetic experience. What MDA categorizes horizontally, outlining the differences between fantasy, competition, etc... Pirsig seeks to qualify vertically, along the axis of his train metaphor. Many aesthetic experiences outlined in the MDA framework could be considered exclusively romantic or exclusively classical, but they all involve psychological phenomena directly related to emotional stimulus of one sort or another. Interactive products that do not produce these emotional experiences are often classified through more abstract language as being "no fun".

\section{Produce Sound Narrative Arcs}

Perhaps most integral to a game's quality is its ability to produce sound narrative arcs. While interactive products, like passive media, are free to explore alternative narrative structures, they are ultimately defined by their relative adherence or deviation from the three-act, archplot structure explained in core narrative theory texts such as Campbell's "Hero With a Thousand Faces” or Robert McKee's "Story. Games that fall under the purview of this aesthetic ideal are not limited to what most consider to be exclusively narrative-driven games that explicitly feature a traceable plotline, discrete set of characters, and expository dialogue or action. As it will be revealed in the subsequent pages of this paper, sound narrative arcs occur also in competitive games, and it is in fact their ability to produce these narrative arcs that is most tied to their perceived quality. 


\section{Arch Plot in the Modern MOBA}

Supplied so far has been an explanation for the contemporary aesthetics and resulting popularity of video games as both active and passive media. It has been asserted that the greater the correlation between a game's most probable outcomes (when played as intended) and an arch plot or Hero's Journey plot structure, the greater its quality. Extracted and applied elsewhere, this thesis can predict engagement in digital products prior to release. The following pages seek to offer explanation for the relative commercial success of digital products as it relates to their application of narrative theory.

Nowhere is the aesthetic value of classical design more apparent than in the structure of a modern MOBA (multiplayer online battle arena) match, where two instances of a three-act archplot (McKee, 1997) take place in direct conflict with each other. Two teams of five compete on a virtual battlefield, and attempt to push their version of the narrative towards a satisfying, irreversible change that affirms the virtues of effective distributed cognition and skilfull determination. What follows is an exhaustive comparison of how the efforts of both teams competing in a MOBA match constitute the path of the hero's journey (Campbell, 2008), resulting in an aesthetically sound viewing experience for the spectator.

\section{The Call To Adventure}

All MOBAs follow a nearly identical pattern of gameplay. The most notable variance is in the average game time length, with League of Legends skewing lower and DOTA 2 higher. In any case, as players sit down to a match, they leave behind the systems 
and paradigms of real life, known colloquially as RL. It is a willing and often exciting departure, when "the hero can go forth of his own volition to accomplish the adventure, as did Theseus when he arrived in his father's city, Athens, and heard the horrible history of the Minotaur" (Campbell, 2008, p. 48). For competitive players, much more of the real world follows them into the game space. Their virtual performances directly affect their fortunes in the world, versus a player who is simply "at play". Regardless, there is a universal transition from the laws and behaviours of RL into that of the game space. This transition, which in fact occurs outside of the game world, constitutes the hero's call to adventure, described by Campbell (2008) as the moment when "the familiar life horizon has been outgrown; the old concepts, ideals, and emotional patterns no longer fit; the time for the passing of a threshold is at hand" (p.43).

MOBAs begin with the character selection phase. Each player is given a choice between a list of champions/heroes/characters that represent not only a unique set of abilities, but also a pivotal role during cooperative play. It can most easily be compared to the positions played in other competitive sports such as quarterback, striker, or goalie. A player's ability to effectively fulfill the role that their chosen character is designated directly impacts their team's chances of victory. It is a loaded and meaningful choice and often involves the entire team huddling together around the captain's monitor for strategic discussion, much like the experience articulated by Campbell (2008) as being characteristic of the call to adventure: "The great ceremonials of investiture divested him of his private character and clothed him in a mantle of his vocation" (p.10) Once the strategic ceremony is completed, the choices are locked in and cannot be altered. 
This interaction also exists outside of the rendered game space. At competitive levels, once players have gone through this "draft", picking characters for themselves and banning characters for the opposing team, the game begins and their characters are instantiated in the game world. In describing the call to adventure, Campbell (2008) reminds us that "Freud has suggested that all moments of anxiety reproduce the painful feelings of the first separation from the mother-the tightening of the breath, congestion of the blood, etc., of the crisis of birth" (p.44) This is a fine analogue for character selection and the beginning of the match, when players enter into a familiar, yet technically new virtual space. When asked what it feels like to play at the level that they do, many competitive eSports players give the same answer: "adrenalin" (Witkowski, 2012) and it is the symptoms of adrenalin, the tightening of breath and congestion of the blood that Freud could just as easily have ascribed to this virtual birth in the game space.

\section{Refusal of the Call}

Campbell (2008) provides numerous examples of mythological characters enduring negative consequences as a direct result of refusing the call to adventure.

A persian city once was "enstoned to stone" - king and queen, soldiers, inhabitants, and all-because its people refused the call of Allah. Lot's wife became a pillar of salt for looking back, when she had been summoned forth from her city by Jehovah. (p.53) 
It occurs when characters are "walled in boredom, hard work, or 'culture', the subject loses the power of significant affirmative action and becomes a victim to be saved" (Campbell, 2008, p.49) The analogue for this behaviour in competitive gaming is "turtling" in which players play "very defensively and (wait) for the opponent to make a move" (Burgun, 2015). In MOBAs specifically, it refers to the phenomena of a team "enstoning" themselves inside their base, under the protection of their defensive structures, in hopes that the opposing team will initiate conflict in such a way that they will make themselves vulnerable. From a spectatorial standpoint, the symptoms of turtling are undesirable:

Matches take longer than optimal. If players are playing defensively, they are slowing down the process of the game. If both players are playing defensively, game lengths can go on for a really long time.

- Matches are less interesting, often un-interactive early on.

- Endgames tend to be a huge, sudden cascade that involves little decisionmaking.

- Some gameplay elements are rendered unusable. (Burgun, 2015)

Narratively, this translates to fewer plot points and removes one of the fundamental elements of the archplot: the active protagonist, described by McKee (1997) as one who, "in the pursuit of desire, takes action in direct conflict with the people and world around him." (p.45) Instead, the team, acting as one cohesive "character" as it pertains to the 
game's narrative, becomes a passive protagonist that is "outwardly inactive while pursuing desire inwardly, in conflict with aspects of his or her own nature.” (McKee, 1997, p.50) This change shifts narrative structure away from classical design, towards antiplot.

To deter players from turtling, designers have gone to great lengths to incentivize active play. Only direct conflict with the other team or intelligent board-control can provide the resources necessary for players to grow in power and eventually become strong enough to overthrow the opposing team's defences and secure victory. Turtling stifles the flow of resources for the team, leaving them weaker than their enemies and vulnerable to attack. This too complies to the internal laws of the hero's journey, where "grace, food substance, energy: these pour into the living world, and wherever they fail, life decomposes into death" (Campbell, 2008, p.32) And so, after answering the call to adventure and eschewing the temptation of refusal, the players seek supernatural aid.

\section{Supernatural Aid}

Players cannot complete their journey without aid. Almost all MOBAs share an economic system through which players accrue resources that can be exchanged for virtual goods specific to the game instance. These goods empower their characters with special abilities and enhancements that allow them to defeat the "many monsters dwelling between here and there... the fabled leviathans, mermaids, dragon kings, and other monsters of the deep" (Campbell, 2008, p.64) For League of Legends and DOTA 2, purchasing magical items is nearly always the first action performed when the game starts. Their choice of purchased items remains relevant the rest of the game, as different items are conducive to different playstyles, and the benefits afforded to players serve them from 
their first encounter to the very end of the match. This step in journey is revisited regularly, as players conquer death through rebirth, which is discussed later in this paper.

\section{The Crossing of the First Threshold}

We stated earlier, the hero's journey represents movement from within the boundaries of comfort and safety, whether those be literal or otherwise, into objectively unsafe territory. This binary of space is well represented in MOBAs. The entire map is geographically delineated by a number of environmental features, each characterized by Campbell (2008) as mainstays of the hero's journey landscape, including "the dark forest, the great tree, the babbling spring..." (p.43) As we'll learn, all three of these settings can be found in the most popular MOBA game maps.

The no-man's land between each team's base is known as the "jungle", which Campbell later points out as being of the many masks adopted by the land beyond the first threshold. He says that "the regions of the unknown (desert, jungle, deep sea, alien land, etc) are free fields for the projection of unconscious content." ( Campbell, 2008, p.65) Vision is limited in the jungle, and it is where monsters are found to be equally hostile to members of either team. It is also where the majority of "team fights" occur, in which members of either team battle each other in hopes of gaining the gold-prizes that come with killing an enemy character. It is where the majority of the team's obstacles must be faced, just as it is for the protagonist of the hero's journey.

At the center of each team's base is their "ancient". Though there are many factors

leading up to it, the win condition of every MOBA game is the destruction of the opposing 
team's ancient. Newer adaptations of the MOBA genre represent the ancient in different ways, but tracing the genre's history back far enough reveals that this was not always the case. MOBAs originated as a Warcraft 3 map, called "Defense of the Ancients". In this original map, the ancient was represented as a literal great tree, just as Campbell describes. It was known in game lore as the tree of life, a core structure of the Night Elf faction.

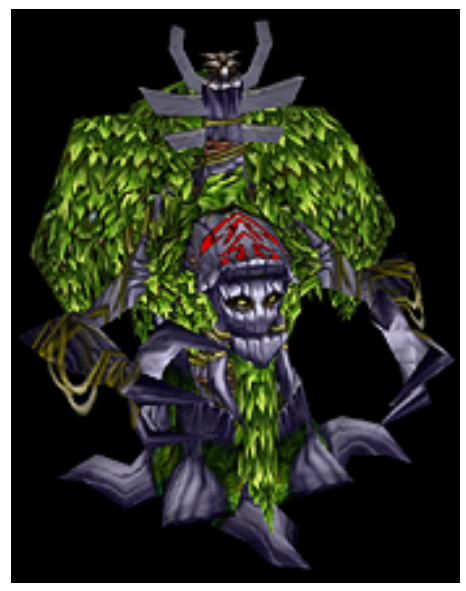

Figure 3

Also present is the "babbling spring". The entire map is divided from the top left corner to the bottom right by a river that serves as a treacherous causeway from one end of no-man's land to the other. It is here that opposing heroes first make contact and the first hero-on-hero conflicts occur. In this way, enemy heroes adopt the role of the "threshold guardians". According to Campbell (2008), "such custodians bound the world in four directions - also up and down - standing for the limits of the hero's present sphere, or life horizon. Beyond them is darkness, the unknown, and danger." (p.64) In the opening stages of play, heroes first encounter each other directly along this axis. Success over the opposing team allows them to progress further, literally passing through the first threshold and forward towards the enemy team's base, or as Campbell (2008) describes it, "the 
crossing of the threshold is the first step into the sacred zone of the universal source" (p.67)

These opening conflicts mark the first appearance of intricate, skilled play. Players rarely know which members of the opposing team to expect, or even how many to expect. Best-practices dictate that characters are evenly distributed between the three "lanes" that lead from one base to the other, but players can never be sure what to expect until they arrive at their own territory's border. "The adventure is always and everywhere a passage beyond the veil of the known into the unknown; the powers that watch at the boundary are dangerous. To deal with them is risky, yet for anyone with confidence and courage, the danger fades" (Campbell, 2008, p.67)

It is also at this first conflict that the player has the opportunity to be punished for being headstrong. Opposing team members are supported by their "towers", defensive structures that damage enemy players that push too deep into their territory. The thrust forward to destroy a tower is known as a "tower dive", and it represents a calculated risk on the part of its perpetrator. They must be able to survive long enough to destroy the tower without being caught or surprised by enemy players, who can capitalize off the support of their friendly tower and kill the enemy hero. Just as it is the case for Campbell's (2008) hero, "though the terrors will recede before a genuine psychological readiness, the over bold adventure beyond his depth maybe shamelessly undone.” (p.68) Death, however undesirable, is a core part of MOBA mechanics and mythology, and can be most 
accurately compared to the stage in the hero's journey that Campbell calls the belly of the whale.

\section{The Belly of the Whale}

When a player is killed, either by an enemy player or their defences, their avatar is removed from the map and they are made to wait as a timer counts down to when they may rejoin the game. For many players, this occurs early in the game, often when attempting to pass the first threshold. "The hero, instead of conquering or conciliating the power of the threshold, is swallowed into the unknown, and would appear to have died."(Campbell, 2008, p.74) Campbell later points out that in many cases, it is not just the appearance of death, but rather that "indeed, the physical body of the hero may be actually slain, dismembered, and scattered over the land or sea," $(2008, \mathrm{p} .77)$ as is the case in MOBAs. Each unique character, once their health is reduced to zero, has an animation in which they are somehow depicted as dying. After death, the player is powerless to affect any aspect of the game, and must watch as their teammates continue play, often at a strategic disadvantage. The entire experience constitutes yet another example of design tailored to aesthetic excellence. The death of the player serves as a beat in their own narrative, the team's narrative, and a narrative in the spectator's experience. The potential for greater reversals of fortune is increased, as the opposing team is given an opportunity to capitalize off of the imbalance of power. Approximate balance is restored, and the hero's journey further enacted, when the player is reborn.

In MOBA play, the word "dying" refers to a player's temporary removal from play, and is inevitably followed by "rebirth": the point at which the player returns to the game. 
"Instead of passing outward, beyond the confines of the visible world, the hero goes inward, to be born again." (Campbell, 2008, p.77) The passage inward is not, by necessity, a strictly negative experience either in MOBA play or the hero's journey. When a player dies, they "may be said to have died to time and returned to the world womb, the world navel, the earthly paradise." (Campbell, 2008, p.77) In dying, players are able to purchase items that will make them more powerful upon returning to play. The only other time this mechanic is available is when their characters are near their ancient, their own world navel, where their character's health regeneration is vastly increased and they can renew themselves with new tools for the trials ahead. Again, we see a nearly exact analogue for this in Campbell (2008), where he states that "allegorically, then, the passage into a temple and the hero-dive through the jaws of the whale are identical adventures, both denoting, in the picture language, the life-centering, life renewing act." (p.77)

\section{The Road of Trials}

Beyond the first threshold lies the road of trials. We find another very literal analogue for this stage in the journey in the form of the "laning phase", described as "the first portion of the game-- (when) minion waves spawn from your nexus and head down towards the three lanes." (Zadorozhnyy, 2012) Substituting a "lane" for the "road", players must push their way along a fraught linear path that leads from their own world navel to that of the opposing team. Along the way they encounter enemy minions, towers, and enemy heroes, and it is only with the help of their tools and teammates that they can gain the momentum they need to succeed later in the game. As Campbell (2008) describes it, "the hero moves in a dream landscape of curiously fluid, ambiguous forms, where he must 
survive a succession of trials... The hero is covertly aided by the advice, amulets, and secret agents of the supernatural helper.” (p.81)

Items and income are the primary metrics of success during the laning phase. The players must incrementally improve their characters as efficiently as possible to prepare for the larger player-on-player battles that occur later in the game. "A well-executed laning phase can set you up for a strong and successful mid game skirmish, while a poor one can cause you to fall behind your opponents in items and force you into a fight at a disadvantage." (Zadorozhnyy, 2012) At this point, protagonists of the hero's journey pursue much the same goal. Campbell (2008) explains how shamans of the northern native tribes prepare for this journey: "His drum is his animal-his eagle, reindeer, or horse; he is said to fly or ride on it. The stick that he carries is another of his aids. And he is attended by a host of invisible familiars.” (p.82) Of the items available for purchase in many MOBAs, drums, sticks, and familiars all appear.

In DOTA 2, the "drum of endurance" increases a hero's attack and movement speed (DOTA Buff, 2015). The "courier" is flying animal that delivers charms and helpful items to the players, and can be customized to appear as any number of creatures including a horse or bird (Gamepedia, 2015). The item systems in MOBAs are so vast that entire statistical databases are dedicated to tracking the success of players that use each item in combination with another. Among the most popular items are vestments and jewels that protect and fortify the player, just as the goddess Inanna is described as using in Sumerian myth. "She adorned herself with her queenly robes and jewels. Seven divine decrees she 
fastened at her belt. She was ready to enter the 'land of no return,' the nether world of death and darkness..." (Campbell, 2008, p.87).

For spectators, the end of this stage of gameplay represents the climax of the first act, in which each of the two protagonists sets out to pursue the object of their desire following the inciting incident. In the case of a MOBA match, we very much start "in medias res", or in the middle of things, and the inciting incident can simply be viewed as the match's commencement. The road of trials, has the potential to encapsulate a vast breadth of narrative beats. It is also where we find what could be the most compelling argument for the presence of the hero's journey in the design of a MOBA match. In continuing his explanation of the Sumerian myth, Campbell describes the confrontation of two mythical sisters.

Inanna and Ereshkigal, the two sisters, light and dark respectively, together represent, according to the antique manner of symbolization, the one goddess in two aspects; and their confrontation epitomizes the whole sense of the difficult road of trials. The hero, whether god or goddess, man or woman, the figure in a mess or the dreamer of a dream, discovers and assimilates his opposite (his own unsuspected self) either by swallowing it or being swallowed. One by one the resistances are broken. He must put aside his pride, his virtue, beauty, and life, and bow or submit to the absolutely intolerable. Then he finds that he and his opposite are not of different species, but one flesh. (Campbell, 2008, p.89) 
Every conflict, either with an enemy character or defence, represents a discovery and assimilation of the other, as described by Campbell above. For the entirety of this first act, players spend their time figuratively "swallowing" each other by defeating the opposition and extracting value from them that they can then use to further bolster their own efforts. This nourishing back and forth is incredibly purposeful and represents a great deal of effort on behalf of the designers to create a system conducive to three-act structure, the second act of which is composed entirely of confrontation, where "the main character encounters obstacle after obstacle that keeps him/her from achieving his/her dramatic need, which is defined as what the character wants to win, gain, get, or achieve..." (Field, 1984) One by one, the enemy defences are destroyed and the story moves into its second act, starting with the meeting with the goddess.

\section{The Meeting With The Goddess}

It is here that the comparison ceases to be quite so overt. Campbell (2008) describes the meeting with the goddess as "the final test of the talent of the hero to win the boon of love (charity: amor fati), which is life itself enjoyed as the encasement of eternity" (p. 97). What we can take from this is not necessarily the romantic or matrimonial context, but rather the comparable effect that cooperation and partnership have on the fortune of the protagonist/players. To Campbell, the goddess acts as an ethical proving grounds for the protagonist. She "represents the totality of what can be known. The hero is the one who comes to know... She lures, she guides, she bids him burst his fetters. And if he can match her import, the two, the knower and the known, will be released from every limitation." (Campbell, 2008, p. 99) In the same way that the goddess demands a "gentle heart" of the 
protagonist if they are to "be released from every limitation", so to does cooperative play demand patience, virtue, and communication between team members if they are to succeed.

As with all team sports, the whole of a MOBA team is greater than the sum of its parts, and it is by the designers' hand that every character is built to fulfill certain responsibilities that complement the efforts of their teammates. For the spectator, this produces some of the most aesthetically charged moments of narrative. It is here, in the second act, that "team fights" start to occur. Team fights are composed of complicated interplay between up to all five players from either team, and require the greatest amount of skill to execute. Those that play "support" characters are tasked with aiding the efforts of the one or more "carries" who must lead the offensive. The intricacies of MOBA team fights are too extensive to exhaustively explore here, but let it be said that a team that can win team fights is implicitly enacting the virtues of the "gentle heart" and are mechanically rewarded with a wealth of opportunity to achieve the object of their desire.

\section{Woman as Temptress}

In the context of MOBA gameplay, the goddess represents one option in the binary choice of how to cooperate as a member of a team. Where the goddess may be said to constitute the abandoning of selfishness and the gentle heart, the temptress represents the inverse, "that pushing, self-protective, malodorous, carnivorous, lecherous fever which is the very nature of the organic cell." (Campbell, 2008, p.102) Again, the female presence is not the defining factor, but rather the temptation towards a baser self, that would have players risk less in favour of self preservation. Mechanically contextualized, this 
constitutes behaviours such as harassment via chat, abandoning fellow players in team fights, or turtling. This attitude, when brought to team fights, undoes a team, and produces some of the most toxic behaviour on record.

\section{Atonement With The Father}

For this stage of the journey, we must step out of the rendered gamespace, to the community surrounding MOBA culture. Riot Games, developers of the massively popular MOBA "League of Legends", in an effort to benefit the experiences had by players and spectators alike, invested substantial resources in the development of a peer-review system that rewarded ideal play behaviours by crowdsourcing judgement of player behaviours they considered undesirable. Endowed with the power of judgement by the game's developers, League of Legends players became the incarnation of righteous judgement among the ranks of players. Among the punishable offences were many behaviours that could be classified as self-protective, malodorous, carnivorous, or lecherous. They included:

- Explicit use of hate terms, racial slurs, cultural epithets, etc.

- Players who deliberately and viciously insult other players.

- Repeatedly negative, non constructive attitudes.

- Players whose teasing crosses the line, and who persist after being asked repeatedly to stop.

- Deliberately disruptive gameplay, such as intentional feeding or otherwise assisting the enemy team. 
- Offensive summoner names.

- Honor trading.

(Riot Games, 2012)

This, in addition to other behavioural improvement initiatives, constitutes the hand of the father at work in the world of mortals. The creators of the game world share the same powers that god is said to possess over the worlds of nearly all mythologies, and to anger them is to tempt fate. Game moderators have the power to permanently ban players from the game, effectively willing them out of existence in the game world, should they behave contrary to "god's wishes". Campbell shares with us the words of the American theologian, Jonathan Edwards: "The Bow of God's Wrath is bent, and the Arrow made ready on the String and Justice bends the Arrow at your Heart, and strains the Bow; and it is nothing but the mere Pleasure of God, and that of an angry God, without any Promise or Obligation at all, that keeps the Arrow one Moment from being made drunk with your Blood..." (Campbell, 2008, p. 105)

Over half of players that were flagged and processed by "The Tribunal", as it was known, did not offend a second time, according to Riot, and they considered the project successful, applying the lessons learned in future player behaviour improvement efforts. The contrition seen in these offending players aligns with Campbell's (2008) transmythological definition of atonement, which he says "consists in no more than the abandonment of that self-generated double monster- the dragon thought to be God (superego) and the dragon thought to be Sin (repressed id). But this requires an 
abandonment of the attachment to ego itself; and that is what is difficult." (p.110) The system has since been taken offline, but in its time served as "a powerful way for the community to decide what behaviors are acceptable during a League of Legends match." (Riot, 2013) For spectators, this meant that more games played out according to ideal narrative structure, making for a better viewing experience.

\section{Apotheosis}

In the internal laws of MOBA game worlds, there exists a discrete ceiling of power above which no character can ascend. Most MOBAs employ a character "level” system that serves as a quantification of strength and abilities. That, combined with the items acquired and any additional enchantments players may have acquired through gameplay, when summed, represent the height of attainable power for any given character. It is at this point that the buildings, monsters, and minions that formerly posed a threat to the character become trivial. The hero becomes a Bodhisattva in miniature, in that "the world is filled and illumined by, but does not hold, the Bodhisattva ('he whose being is enlightenment'); rather, it is he who holds the world, the lotus. Pain and pleasure do not enclose him, he encloses them- and with profound repose." (Campbell, 2008, p.129) This is the moment of apotheosis, where players reach the apex of their potential as defined the be designers of the game. So great is their power that it is only the other players, also having achieved their maximum potential, that pose a threat. Campbell (2008) articulates it well, saying that "like the Buddha himself, this godlike being is a pattern of the divine state to which the human hero attains who has gone beyond the last terrors of ignorance." (p.130) 


\section{The Ultimate Boon}

The rules of the of the game world dictate that there can be no greater success other than the achievement of the game's win-condition, which at all times remains the destruction of the opponent's ancient/nexus/tree. It is the game world's "ultimate boon", and as Campbell (2008) tells us, “the Buddha's victory beneath the Bo Tree is the classic Oriental example of this deed. With the sword of his mind he pierced the bubble of the universe - and it shattered into nought. The whole world of natural experience, as well as the continents, heavens, and the hells of traditional religious belief, exploded - together with their gods and demons." (p.164) It is in the achievement of this task that the game world, like the world of the Buddha, is destroyed. It is cleared from memory in the computers of each networked participant once they have each disconnected following the game's conclusion. Players are once again made members of the real world, presented with its familiar sets of laws and paradigms.

Following this conclusion, we can look back to discover in MOBAs, the hero's journey in miniature: "The agony of breaking through personal limitations is the agony of spiritual growth. Art, literature, myth and cult, philosophy, and ascetic disciplines are instruments to help the individual past his limiting horizons into spheres of ever-expanding realization. As he crosses threshold after threshold, conquering dragon after dragon, the stature of the divinity that he summons to his highest wish increases, until it subsumes the cosmos.” (Campbell, 2008, p.163) 


\section{Conclusion}

As one of the most rapidly evolving and semantically mercurial mediums of modern civilization, it is critical that a flexible, interdisciplinary approach be employed in the development of critical thinking as it relates to the study of video games. Too often academics and industry professionals restrict their thought to one discreet theoretical system or framework of analysis, the singularity of which inevitably confounding their efforts to effectively analyze a medium that is characterized by its capacity to contain and produce multitudes. Through Pirsig's application of Eastern philosophical principles, he is able to distil a new understanding of quality much more analogues to the feedback loop at the core of every interactive experience, atop which we are able to construct a much more effective vocabulary of analysis through the more system models of analysis found in flow, MDA, and contemporary narrative theory.

The narrative arc of the contemporary MOBA should be considered one of the longer, more drawn out instances of narrative arcs as they appear in traditionally nonnarrative based games. The same dramatic structure can be found in games as simple as rock, paper, scissors, and it is the author's hope that through this newly synthesized aesthetic framework, the reader will be more inclined to note them as they appear in future interactive texts. 


\section{References}

1. Burgun, K. (2015) Turtling. Retrieved from http://www.gamasutra.com/blogs/KeithBurgun/20150505/242620/Turtling.php

2. Campbell, J. (2008). The hero with a thousand faces. Novato, California: New World Library.

3. Csikszentmihalyi, M. (1990). Flow : the psychology of optimal experience. New York: Harper \& Row.

4. Dota 2 Wiki, (2015) Custom Courier http://dota2.gamepedia.com/Custom Courier

5. Elo Entertainment, (2015) Drum of Endurance. Retrieved from https://www.dotabuff.com/items/drum-of-endurance

6. Field, S. (2005). Screenplay : the foundations of screenwriting. New York, N.Y: Delta Trade Paperbacks.

7. Gumbrecht, H. (2006). In praise of athletic beauty. Cambridge, Mass: Belknap Press of Harvard University Press.

8. Hunucke, R. \& LeBlanc, M. \& Zubek, R. (2009) MDA: A Formal Approach To Game Design and Game Research. Retrieved from http://www.cs.northwestern.edu/ hunicke/MDA.pdf

9. Jones, S. (2011) League of Legends Reveals Tribunal Statistics to Punish or Pardon Reported Players. Retrieved from http://www.tentonhammer.com/leagueoflegends/news/league-of-legends-revealstribunal-statistics-to-punish-or-pardon-reported-players

10. Llamas, S. \& James, R. (2015). eSports Market Brief Update 2015-2016 Retrieved from https://www.superdataresearch.com/blog/esports-brief/ 
11. McCloud, S. \& Lappan, R. (1999). Understanding comics. New York: Paradox Press.

12. McKee, R. (1997). Story : substance, structure, style and the principles of screenwriting. New York: ReganBooks.

13. Morgan, A. \& Barden, M. (2015). A beautiful constraint : how to transform your limitations into advantages, and why it's everyone's business. Hoboken, New Jersey: John Wiley \& Sons, Inc.

14. Pirsig, R. (1991). Lila : an inquiry into morals. New York: Bantam Books.

15. Pirsig, R. (2009). Zen and the art of motorcycle maintenance : an inquiry into values. Pymble, NSW New York: HarperCollins e-books.

16. Riot Games, (2013) Upgrading the Tribunal. Retrieved from http://euw.leagueoflegends.com/en/news/game-updates/player-behavior/upgradingtribunal

17. Rogerson, Melissa J.; Gibbs, Martin; Smith, Wally; Digitising Boardgames: Issues and Tensions Retrieved from http://www.digra.org/wp-content/uploads/digitallibrary/66_Rogerson-etal_Digitising-Boardgames.pdf

18. Strunk, W. (2006). The elements of style. United States: Filiquarian Publishing. 19. Witkowski, E. (2012) On the Digital Playing Field: How We "Do Sport" With Networked Computer Games

20. Zadorozhnyy, A. (2012) A beginner's guide to laning Retrieved from http://www.team-dignitas.net/articles/blogs/League-of-Legends/1218/A-beginnersguide-to-laning 


\section{Ludography}

1. Riot Games. (2009). League of Legends [video game]

2. Valve Corporation. (2013). DOTA 2 [video game]

3. Blizzard Entertainment. (2002).Warcraft 3: Reign of Chaos [video game]

4. Feak, S. \& Eul \& IceFrog (2003). Defense of the Ancients [video game mod/map] 